\section{BOS UPDATES ITS GUIDANCE ON SUPERVISION OF ORTHODONTIC THERAPISTS}

The British Orthodontic Society (BOS) has updated its guidance on the supervision of orthodontic therapists (OTs). More than 400 OTs have been trained and entered the orthodontic workforce in the last ten years and the number of OTs qualifying annually now exceeds the number of orthodontists completing postgraduate training.

The guidance is important to support the way that orthodontic teams operate in the workplace and also to underpin the training of both orthodontists and OTs. As the OT role has become more established, it's increasingly important for the guidance to help team members work both safely and in the most efficient way possible.

The key issue, said Simon Littlewood, a member of the working party responsible for updating the guidance and an orthodontic consultant, is that the OT must work to the prescription of an orthodontist. He said the prescription could be a verbal one or, if the orthodontist could not be present, there could be a detailed prescription in the patient's notes. The patient should never go for more than one appointment without seeing the orthodontist.

He said the role, which was introduced ten years ago, had been a valuable addition to the skill mix: "The orthodontist can focus on the diagnosis and treatment planning, while closely overseeing the OT undertaking the practical aspects of the treatment, which OTs are so well trained to undertake. These new guidelines are all about sensible, safe and efficient use of the skill mix in orthodontics, making appropriate use of the knowledge and skills of different members of the orthodontic team for the benefit of our patients.

The original guidance was written by a BOS team when the role achieved recognition from the General Dental Council, and was first updated in 2012. This latest 2017 update is expected to be the touchstone for training of all orthodontic teams for a few years to come.

To view the guidance visit http://www. bos.org.uk/Professionals-Members/ Members-Area-Publications-GeneralGuidance/Information-and-Advice/ General-Guidance/Supervision-ofOrthodontic-Therapists.

The 30th British Orthodontic Conference will be held in Manchester on 14-16 September 2017. Highlights this year include 'The Great Digital Debate'; Nigel Harradine speaking on 40 years in orthodontics; and lingual orthodontist Professor Dirk Wiechmann as Northcroft lecturer. http:// www.bos.org.uk/BOC-Manchester-2017

\title{
Philips
}

\section{encouranges dental \\ hygienists to shime}

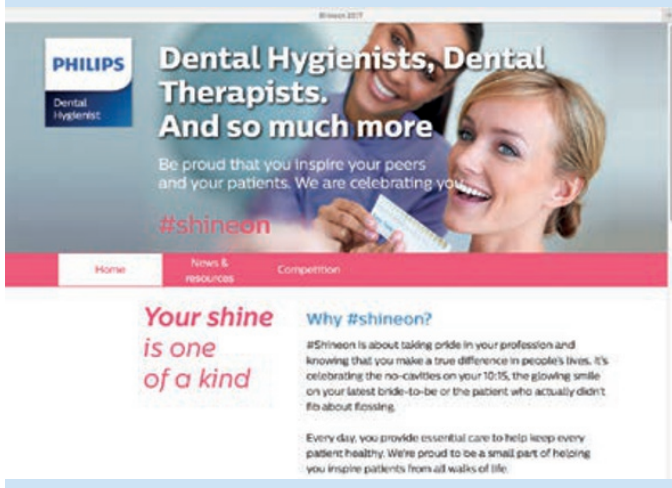

Philips Oral Healthcare is showing its appreciation of dental hygienists and their commitment to improving the oral care of their patients through its new 'Shine On' initiative.

As the centrepiece of the campaign, Philips has launched a digital hub at www.philips.co.uk/shineon featuring video testimonials, industry news, educational resources and a Shine On sweepstakes with giveaways exclusively for dental hygienists.

Dr Maha Yakob, Global Director, Professional Relations \& Scientific Affairs at Philips Oral Healthcare said: 'The idea behind Shine On is to celebrate dental hygienists and provide a platform for them to lift each other up, too. It's about taking pride in your profession and knowing you make a real difference in people's lives'.

Dental hygienists are invited to participate by sharing their own Shine On moments on social media, tagging their posts with \#shineon and \#philipssonicare. Their collective Facebook, Instagram and Twitter posts will help populate a social media feed on the Shine On website.

Philips is also supporting the initiative with trade show promotions, print and social advertising and outreach via dental hygienist bloggers.

www.philips.co.uk/shineon 